\title{
Effects of Technology-Based Teacher Training and Teacher-Led Classroom Implementation on Learning Reading Comprehension Strategies
}

\author{
Michael Graves \\ University of Minnesota, United States \\ Gregory C. Sales \\ Seward Incorporated, United States \\ Frances Lawrenz \\ University of Minnesota, United States \\ Beth Robelia \\ Kitchen Table Learning, United States \\ Jayson W. Richardson \\ University of Kentucky, United States
}

\begin{abstract}
This study examined the effectiveness of a professionally developed comprehensive reading comprehension strategies program when compared to traditional reading comprehension instruction presented to 865 fourth and fifth graders (682 with full data sets) in 34 classrooms in the United States. The treatment included a strong, technology-based teacher training component as well as highly motivational materials for 53 classroom-delivered student lessons. The research design was a randomized trial at the classroom level, with classes randomly assigned to either the treatment (classroom $n=17$ ) or control (classroom $\mathrm{n}=17$ ) conditions. Hierarchical Linear Modeling was performed on student achievement data, nested within classrooms within treatment conditions, for the intact classes. HLM analyses using experimenter-designed achievement tests as the outcome variable showed a significant effect for condition, with students in the treatment condition scoring higher than students in the control condition across all the different student groups (gender, ethnicity, and English Language proficiency).
\end{abstract}

Keywords: DVD; Teacher training; Reading comprehension; Strategies

\section{Introduction}

Many U. S. students are not developing the sophisticated reading comprehension skills crucial to success in the 21st century. National Assessment of Educational Progress (NAEP) assessments of 
literacy (e.g., Lee, Grigg, \& Donahue, 2007; Perie \& Moran, 2005), NAEP assessments of history (Lee \& Weiss, 2007), international comparisons (e.g., Kennedy, Mullis, Martin, \& Trong, 2007; Programme for International Student Assessment (PISA), 2004), and the findings of prestigious national study groups (National Reading Panel, 2000, RAND Reading Study Group, 2002; Biancarosa \& Snow, 2004; Kamil, Borman, Dole, Kral, Salinger, \& Torgesen, 2008; National Association of State Boards of Education, 2005; ACT, 2006) all support this conclusion. As the authors of the RAND Reading Study Group have explicitly and forcefully pointed out, "The demand for literacy skills is high and increasing. The U. S. economy demands a universally higher level of literacy achievement than at any prior point in history, and it is reasonable to believe that literacy demands will increase in the future" (p. 4).

However, while the demand for sophisticated reading comprehension skills is high and increasing, the reading skills of U. S. students have remained nearly unchanged over the past 30 years (Perie \& Moran, 2005; RAND, 2002). In the words of the RAND Reading Study Group, the performance of U. S. students remains "stagnant" (p. 5). Moreover, the gaps between middle-class, European American children and children of poverty, English-language learners, and Black, Hispanic, and Native American children are large and persistent (Lee, Grigg, \& Donahue, 2007; Lee \& Weiss, 2007; RAND, 2002).

The specific problem motivating the research described here is that few $\mathrm{U}$. S. students are being taught the reading comprehension strategies they need in order to do the sophisticated reading required in today's world (Duffy, 2002; Pressley, 2006; RAND, 2002). This is the case for the following reasons:

- Teaching reading comprehension strategies was not a part of the whole language agenda, which greatly dominated in U. S. classrooms throughout most of the last decade (Pearson, 2000), and thus teaching comprehension strategies was simply not a priority during the decade.

- Teachers have not been adequately trained to teach reading comprehension strategies (Graves \& Philippot, 2002; RAND, 2002).

- Even with training, teaching comprehension is very challenging (Duffy, 2002; Pressley, 2002; RAND, 2002).

- For most teachers, successfully teaching comprehension strategies is dependent on having appropriate and powerful materials to use in teaching the strategies (Graves \& Liang, 2003; Graves, Juel, \& Graves, 2007).

Research on the nature of reading comprehension strategies, which strategies are effective, and how to effectively teach reading comprehension strategies, informed both the design of the treatment materials for the present study and the study itself (see, for example, Israel \& Duffy, 2008).

Reading comprehension strategies are "conscious and flexible plans that readers apply and adapt to a variety of texts and tasks" (Pearson, Rohler, Dole, \& Duffy, 1992, p. 169). They are processes readers engage in for the purpose of better understanding and remembering what they read. One 
strategy, for example, is determining what is important, that is, deciding which of the numerous concepts in any reading selection deserve special attention. Particularly when reading informational material to gain knowledge on a topic, readers must determine just what it is they need to learn. One way to do so is to read the introduction and summary, and another way is to skim through the material seeing what was highlighted in the headings and subheadings. Readers who are adept at determining what is important in a reading selection have these and a variety of other strategies available, and they employ whichever strategies best fit each reading situation they encounter. For all students -including able students, English-language learners, and students who struggle in reading-strategies lead to independence in reading.

While different authorities suggest slightly different lists of strategies to teach, there is substantial agreement on the matter. The following nine strategies have been identified as useful and important to teach based on research, reviews of research, and their inclusion in instructional materials (Duffy, et al. 1987; Ellery, 2005, Making Meaning, 2003; Gambrell, 2007; National Reading Panel, 2000; Pearson et al., 1992; Pressley, 2000; RAND, 2002;): having a purpose, recognizing text structure, using prior knowledge, making inferences, questioning, predicting, determining what is important, summarizing, and being metacognitive.

Over the past 15 years, a substantial body of theory and research has supported two approaches to teaching comprehension strategies-"direct explanation of strategies" and "transactional strategies instruction." Direct explanation of strategies has been repeatedly validated and endorsed over the past two decades (e.g., Duffy, 2002; Duffy et al., 1987; Duke \& Pearson, 2002; Graves et al., 2007; National Reading Panel, 2000; Pearson et al., 1992, RAND, 2002). Direct explanation of strategies is a very explicit, step-by-step approach. A typical unit used to initially teach a strategy-for example, a unit on summarizing-might last three weeks. Gradually, over those three weeks, the instruction progresses from a situation in which the teacher does most of the work to one in which students assume primary responsibility for use of the strategy.

Transactional strategies instruction is in some ways an offshoot of direct explanation. It too has been described and researched in a number of studies (e.g., Brown, Pressley, Van Meter, \& Schuder, 1996; Pressley, 2000, 2002, 2006; Pressley, et al., 1992; Reutzel, Fawson, \& Smith, 2003). Like direct explanation of strategies, transactional strategies instruction includes direct explanation as part of the initial instruction on strategies. However, as compared to direct explanation, transactional strategies instruction is much less structured and heavily embedded in the ongoing reading activities in the classroom. There is solid evidence that transactional instruction is effective, and such instruction has been shown to be particularly useful in giving students approaches that they use in their actual reading in and out of school (e.g., Anderson, 1992, Pressley\& El-Dinary, 1997, Reutzel et al., 2003). However, there is also clear evidence that relatively few teachers can and do learn to use transactional strategies instruction (Pressley \& ElDinary, 1997; Pressley, 2002). Because it is an "on the fly" approach and is typically not supported by specific curriculum and instructional materials, teachers have found it very difficult to work transactional strategies instruction into the school day.

While both of these teaching strategies have been shown to be effective, neither of them by itself include everything necessary to ensure the competence motivation, engagement, confidence, and commitment needed for students (particularly students who have struggled with reading) to 
become independent and self-regulating life-long users of strategies. The comprehension strategy instruction used in the research treatment combines the best features of direct explanation of strategies and transactional strategies instruction with the latest research-based techniques for promoting motivation and engagement (e.g., Elliot \& Dweck, 2005; Guthrie, Wigfield, \& Perencevich, 2004; National Research Council, 2004).

Unfortunately, preparing teachers to use either direct explanation or transactional strategies instruction is a sizeable task requiring expert trainers. In past studies of comprehension strategies instruction, the teacher training has typically been done by the researchers. Of course, researchers are not available to train the large numbers of teachers who need to provide comprehension strategy instruction for their students, and in fact most districts cannot afford to pay expert trainers to prepare their teachers even if expert trainers were available. A major purpose of this study, therefore, was to prepare teachers using a self-paced, media-rich, interactive DVD that included a number of video vignettes modeling reading comprehension strategy instruction.

Four primary research questions were developed for this study. They are:

1. Will users of the treatment DVD find it easy to use, appealing, and valuable?

2. Does the DVD prepare teachers to teach the reading comprehension strategies?

3. Does the treatment improve students' ability to use comprehension strategies?

4. Will students find the treatment materials appealing and easy to use?

\section{Methodology}

\section{Participants}

In order to answer the research questions, 34 fourth and fifth grade classrooms from nine different schools in a major metropolitan area were selected and randomly assigned to either a treatment or control condition. The 865 students ( 682 with full data sets) in these 34 classrooms (17 treatment classrooms and 17 control classrooms) represented a range of socioeconomic, racial, and linguistic backgrounds (Table 1). The treatment teachers and students used the instructional materials we developed, while the control classes used their traditional reading programs.

Table 1: Demographic Data by Group

\begin{tabular}{|l|l|l|}
\hline & Treatment $\mathbf{N}=\mathbf{4 3 9}$ & Control N=426 \\
\cline { 2 - 3 } & Percent & Percent \\
\hline Sex & & \\
Male & 50.6 & 50 \\
Female & 49.4 & 50 \\
& & \\
\hline
\end{tabular}




\begin{tabular}{|l|r|r|}
\hline Race & & \\
African American & 14.3 & 17.4 \\
American Indian & 0.6 & 1.8 \\
Asian & 15.3 & 11.1 \\
Hispanic & 8.2 & 6.9 \\
White & 59.6 & 59.9 \\
Other & 1.7 & 3.0 \\
\hline English Language & \\
Learning English & & \\
Native Speakers & 26.1 & 18.0 \\
& 73.9 & 82.0 \\
\hline
\end{tabular}

\section{Treatment Materials}

A team of professional curriculum developers (videographers, photographers, on-screen talent, programmers, graphic artists, editors, page layout specialists), working with experts in reading instruction and evaluation, created the treatment materials. The final package of treatment materials provided all the resources required for teacher training and the delivery of 13 weeks of instruction (spaced over 28 weeks of the school year) to teach nine crucial reading comprehension strategies to fourth and fifth graders. The materials were centered around the theme of archeology, which was reflected in graphics and lesson analogies.

The teacher training consisted of a self-paced, media-rich, interactive DVD. The DVD was designed to introduce teachers to the treatment materials, educate them on reading comprehension issues, present content on direct explanation and transactional instructional methods, as well as to prepare them specifically for delivery of the instructional treatment lessons. The training DVD explained nine strategies identified by researchers as critical for reading comprehension and central to the treatment instruction. In addition to video vignettes addressing reading comprehension and design of the treatment materials, the DVD contained approximately 50 video vignettes of teachers demonstrating effective use of instructional techniques while teaching with the treatment materials.

A number of resources were also included to support teachers during the classroom implementation. These included:

- a detailed teacher guide that provided clear support for each lesson, including icon links back to the video modeling on the DVD

- weekly quizzes, unit-level quizzes, and a final test

- 10 posters for display in the classroom at appropriate times, one covered all nine strategies, the others each addressed one of the strategies being taught, and

- 52 overhead transparencies used at various times during the delivery of the classroom training. 
The structure used in the teacher's guide to prepare the teachers to teach each lesson consisted of six components. The guide detailed the approach and provided resources teachers were to use when presenting the lessons to students. These materials also keyed teachers to the video resources that demonstrated specific teaching behaviors. Components addressed in the training were:

- Focus - Every lesson begins with a Focus activity. Here, the teacher captures students' attention with a game, thought-provoking questions, or a brief review. Motivation is addressed throughout the lesson, but it is an especially important element of the Focus, when teachers explain why a strategy is useful.

- Teach/Model - In the Teach/Model activity, the teacher provides a description of the strategy and information on when, where, and how it should be used. The teacher then demonstrates the strategy by thinking aloud while reading to the students. Teaching and modeling is especially important early in the week, when students are introduced to a new strategy.

- Guide - The Guide activity provides a bridge between teachers demonstrating and students working on their own. In the Guide activity, the teacher interacts with the class as a whole. He or she usually reads aloud and guides students to use a strategy by prompting them with questions.

- Practice/Apply - Students practice using a strategy, either independently or with a partner. As the week progresses, more lesson time is devoted to this type of activity.

- Summarize - All lessons end with a summary of the key messages. Teachers ask students to reflect on how well the strategy is working and when and how they can use it in the future.

- Assess - Students take a quiz on Day 4 of every week. In Weeks 1 and 2, the quiz covers only the strategy taught that week. The quiz for Week 3 is more extensive and covers all the strategies taught thus far.

Treatment materials for the students consisted of 53 teacher-delivered lessons designed to be highly motivational. Each lesson was theme-based (incorporating some element from archeology), contained age-appropriate visual elements, and incorporated one or more active learning techniques. In addition, each student received an activity book with each unit of instruction. The activity books had colorful covers with archeology icons representing the strategies addressed in that unit and enabled each student to keep her or his unit-related work in a single location.

\section{Intervention}

Lessons were structured around the two proven instructional approaches previously describeddirect explanation and transactional strategies instruction. Accurate delivery of the instruction was crucial to implementation of the treatment intervention. The teacher training DVD was 
delivered to teachers for self-study approximately 3 weeks prior to the classroom implementation. Teachers were required to complete all of the training prior to teaching any of the lessons. Videos showing how teachers and students engaged in the lessons were an important part of the DVD. Teachers were encouraged to refer back to the DVD to review strategies as they prepared to teach each lesson.

As noted, capturing and maintaining students' interest in reading was seen as crucial to their success with the materials, and the treatment materials therefore emphasized motivation and engagement:

- Each lesson began with an activity designed to capture students' attention, such as a game or thought-provoking questions.

- In the lessons, teachers explained to students why reading comprehension strategies are important.

- $\quad$ Students practice the strategies in authentic texts by contemporary authors.

The archeology theme used throughout the treatment materials was chosen to draw students in and add an element of adventure. The theme provides a metaphor for learning about the strategies-each strategy was associated with an archaeologist's tool. For example, a rope is associated with Using Prior Knowledge to remind students to "make connections." Characters throughout the student activity books, classroom posters, and overheads were engaged in archeological tasks using the tools associated with each reading comprehension strategy.

As noted, the students' curriculum was comprised of 53 lessons grouped into five units. Each lesson required 30-45 minutes to complete. The first unit required 4 days to complete. Each of the remaining units required 12 days, over three weeks, to complete. The five units, containing 13 weeks of instruction, were spaced across 28 weeks of the school year to allow students 3 weeks between units to apply the strategies they had thus far learned before going on to learn new ones. In addition, archeology-themed posters displaying the strategies students had learned were displayed prominently in the classrooms to remind students to use their new reading comprehension tools.

\section{Student Measures}

Students were pre- and post-tested using experimenter-designed assessments. The assessments contained knowledge and application questions focused on each of the nine reading comprehension strategies taught in the treatment curriculum. The pre-test consisted of 12 items, 10 of which were three-option multiple-choice questions. Of the remaining two questions, one asked students to describe how they make an inference. The other required students to identify a clue within a passage that enabled them to make a prediction about what would happen later in the story.

The post test consisted of 35 items, 16 of which were three-option multiple-choice questions and 17 of which were free response. Nine of the free-response questions required students to write a 
few phrases or a sentence and eight required students to apply comprehension strategies to a brief passage to arrive at a correct response.

In addition to the experimenter-designed assessments, students' scores on the reading portion of Minnesota Comprehensive Assessment were obtained for the April 2006 and the April 2007 administrations. Students in treatment classrooms also completed surveys asking what strategies they had learned and how well they liked the curriculum.

\section{Teacher Measures}

Teachers in both conditions were post-tested on their knowledge of reading comprehension strategies. Additionally, pre- and post-surveys monitored how teachers' attitudes about reading comprehension instructions may have shifted due to use of the treatment curriculum. Teachers using the treatment materials were also asked to evaluate the curriculum on usability, student appeal, and effectiveness via open-ended questions at the end of the post-survey.

Teachers were observed by the research team once during each of units 2, 3, 4 and 5 . Observations were conducted in order to determine how the curriculum was being implemented and to monitor firsthand the effectiveness of lessons in engaging students. In addition to classroom visits, students in treatment classrooms were given surveys that asked about what took place in their classroom. Both classroom visits and student survey responses confirmed that the treatment was implemented as intended.

\section{Data Analysis}

Two hierarchical linear modeling (HLM) analyses were conducted. The first HLM analysis used the student post-test scores from the experimenter-designed assessment as the outcome variable, with the experimenter-designed pre-test designed as one of the level one variables. The second HLM analysis used the Minnesota Comprehensive Assessment (MCA) scores as the outcome variable, with the pre-treatment MCA score as a level one variable. Other level one student variables were gender, ethnicity, and English language learning status (native speaker or not) as well as the pre-test knowledge scores. Level two teacher variables were teacher knowledge score and experimental or control condition.

\section{Findings}

\section{HLM analyses}

HLM analyses conducted using the experimenter-designed achievement tests as the outcome variable showed a significant effect for condition, with students in the treatment condition scoring higher than students in the control condition across all student groups (gender, ethnicity, and English Language proficiency). (See Tables 2, 3, and 4, below, for the post-test scores.) The student pre-test score was also a significant predictor of student final achievement. Teacher 
knowledge was a significant variable in affecting the relationship between boys' and girls' knowledge scores. The findings indicate that teacher knowledge of the strategies tends to ameliorate the traditional differences between girls and boys in reading; that is, it appears that knowledge of the strategies helps teachers to help boys learn.

Table 2: Average Post-test Score and Standard Deviation by Experimental Group and Gender

\begin{tabular}{|l|l|l|l|l|}
\hline \multirow{2}{*}{} & \multicolumn{2}{|l|}{ Treatment } & Control \\
\cline { 2 - 5 } & Average Score & $\mathbf{N}$ & Average Score & N \\
\hline Male & $25.20(5.09)$ & 177 & $16.86(4.16)$ & 167 \\
\hline Female & $25.99(5.06)$ & 173 & $17.85(4.04)$ & 167 \\
\hline
\end{tabular}

Table 3: Average Post-test Score and Standard Deviation by Experimental Group and Race

\begin{tabular}{|l|l|l|l|l|}
\hline \multirow{2}{*}{} & Treatment & Control & N \\
\cline { 2 - 5 } & Average Score & $\mathbf{N}$ & Average Score & N \\
\hline African American & $23.34(5.63)$ & 50 & $15.75(4.63))$ & 58 \\
\hline American Indian & $19.75(8.13)$ & 2 & $18.66(2.66)$ & 6 \\
\hline Asian & $25.76(5.02)$ & 54 & $14.70(3.92)$ & 37 \\
\hline Hispanic & $22.09(5.42)$ & 29 & $17.56(3.84)$ & 23 \\
\hline White & $26.57(4.55)$ & 208 & $18.46(3.56)$ & 200 \\
\hline Other & $27.37(0.85)$ & 4 & $13.10(4.41)$ & 10 \\
\hline
\end{tabular}

Table 4: Average Post-test Score and Standard Deviation by Experimental Group and ELL Status

\begin{tabular}{|l|l|l|l|l|}
\hline \multirow{2}{*}{} & \multicolumn{2}{|l|}{ Treatment } & Control \\
\cline { 2 - 5 } & Average Score & $\mathbf{N}$ & Average Score & N \\
\hline Learning English & $24.57(5.41)$ & 91 & $15.31(4.20)$ & 60 \\
\hline Native Speaker & $25.96(4.93)$ & 257 & $17.80(3.99)$ & 274 \\
\hline
\end{tabular}

Similar HLM analyses conducted using the MCA tests as the outcome variable showed no differences between treatment and control groups; however, the pretest score was a significant predictor of the final achievement score. Given the broad and distal nature of the MCA tests, the authors were not surprised by the lack of treatment effect on MCA scores.

There was a significant correlation between the post MCA score and the experimenter-designed post-test scores. For fourth grade the correlation was $r=.50,(p<.01)$. Fifth grade showed a lower but still significant correlation $r=.36(p<.01)$. 


\section{Other Assessments}

When test items were sorted by the nine reading comprehension strategies, students using the treatment materials did better than those in the control group on every strategy, with effect sizes ranging from $d=0.4$ to $d=1.8$.

Teacher knowledge test scores were compared between treatment teachers and the control group. The treatment teachers had significantly more knowledge of reading comprehension strategies than their peers in the control group $d=3.0[t(21)=8.83, p<.001]$. In addition to the HLM, regression analyses were conducted. These showed that teachers' scores on the knowledge of reading comprehension post-test predicted their students' post-test scores, $F(1,32)=26.44, p$ $<0.001$. The model had an adjusted $R^{2}$ of 0.43 , indicating $43 \%$ of the variance in student scores was accounted for by teacher post-test scores. In other words, teachers with higher post-test scores had students with higher post-test scores. Post-treatment surveys indicated that neither the treatment nor the control teachers showed a change in attitudes, nor were there differences between the teachers in the two groups. Teacher attitude scores were not predictive of student achievement scores. Teachers in both groups had consistently positive attitudes to begin with, and these positive attitudes remained throughout the project.

Teachers and students in the treatment condition were also asked their opinions about the curriculum materials. The responses regarding usability and appeal were largely positive. Of the teachers who used the treatment materials, 95\% would recommend them to a colleague. Their responses to open-ended questions indicated they enjoyed teaching the curriculum and thought their students learned a great deal. Students were asked about materials in a survey they completed after finishing all of the lessons. Over $80 \%$ of the students agreed to a statement indicating the comprehension activities they did in class helped them understand the stories. More than $70 \%$ of the students thought their peers would enjoy using the materials. A majority of the students found the pictures in the student activity book interesting. When surveyed about the reading comprehension strategies, well over $80 \%$ of the students agreed they had learned each of the strategies (see Table 5 below).

In addition to statistical data, teachers were asked for their overall impressions of the treatment curriculum on an evaluation survey. One of the fourth grade teachers replied, "Wow! The knowledge gained was unbelievable. I see my students using the strategies in all other subjects. The archaeology theme was perfect for our grade level." Another teacher commented, "I really enjoyed teaching it to the kids. It really was worth my time and I feel [the treatment instruction] beneficial to the kids." This teacher's comments sums up many others: "I think the Digging Reading Program is an excellent resource for teaching comprehension."

When asked about the appeal of the product, students' responses were generally positive. The stories around which the curriculum was developed were identified as interesting by $62 \%$ of the students. Students said the activities were fun (61\%). In addition, $63 \%$ of the students agreed or strongly agreed that other students would enjoy the lessons. 
Table 5. Percent of Students Agreeing They Had Learned a Reading Comprehension Strategy

\begin{tabular}{|c|c|}
\hline Survey Statement & $\begin{array}{l}\text { Percent of Student } \\
\text { Agreeing to the } \\
\text { Statement }\end{array}$ \\
\hline I learned the difference between narrative and expository text. & 92 \\
\hline I learned why having a purpose for reading is important. & 91 \\
\hline I learned to use my prior knowledge while reading. & 88 \\
\hline I learned to ask questions while I am reading. & 87 \\
\hline $\begin{array}{l}\text { I learned to make inferences using clues from the text and prior } \\
\text { knowledge. }\end{array}$ & 83 \\
\hline $\begin{array}{l}\text { I learned to predict what will happen next in a story by using clues the } \\
\text { author gives. }\end{array}$ & 86 \\
\hline I learned more about summarizing what I read. & 82 \\
\hline The stories we read were interesting. & 62 \\
\hline The activities we did in class were fun. & 61 \\
\hline Other students would enjoy these lessons. & 63 \\
\hline
\end{tabular}

\section{Conclusion}

Based on the analyses described above, it is clear that the treatment intervention has the potential to improve teacher skills in teaching reading comprehension and students' knowledge and use of reading comprehension strategies. By way of conclusion, we will briefly discuss the results in terms of our research questions.

"Will users of the treatment DVD find it easy to use, appealing, and valuable?" From the results of the evaluation questions on the post-implementation teacher survey, many teachers found the video vignettes especially helpful. One replied, "To hear teachers model the way to talk about strategies was very helpful. I used them as my models." Teachers also thought the format was valuable, making it easy to review the videos related to a lesson before they taught it. Teachers commented that the introduction to the treatment provided by the DVD helped them understand the organization of the lessons. Other teachers noted that having electronic copies of all the lesson materials on the DVD made it easier to use.

"Does the DVD prepare teachers to teach the reading comprehension strategies?" Results from the pilot show that teachers who used the treatment DVD learned more reading comprehension strategies than their peers in the control groups. The ten-item teacher knowledge test on reading comprehension strategies asked teachers about the nine reading comprehension strategies that are included in the DVD. The teachers in the experimental group had significantly greater understanding of the strategies than teachers in the control group.

When asked on an evaluation survey for their overall impressions of the treatment curriculum teachers were both enthusiastic and positive in their responses. One of the fourth grade teachers 
replied, "Wow! The knowledge gained was unbelievable. I see my students using the strategies in all other subjects. The archaeology theme was perfect for our grade level." Another teacher commented, "I really enjoyed teaching it to the kids. It really was worth my time and I feel [the treatment instruction] beneficial to the kids." This teacher's comments sums up many others: "I think the Digging Reading Program is an excellent resource for teaching comprehension." These responses suggest the materials were easy to use and surpassed teachers' expectations on effectiveness.

"Does the treatment improve students' ability to use comprehension strategies?" HLM analyses conducted using the experimenter-designed achievement tests as the outcome variable showed that students in the treatment condition scoring significantly higher than students in the control condition across all the different student groups (gender, ethnicity, and English Language proficiency). Additionally, when test items were sorted by the nine reading comprehension strategies, students using treatment materials did better than the control group on every strategy.

"Will students find the treatment materials appealing and easy to use?" Observations in classrooms and responses on the student survey indicate the majority of the students participating in the research found the stories interesting, the activities were engaging, and that participants thought other students would enjoy the lessons.

Based on these findings, we strongly recommend the use of professionally developed reading comprehension strategies programs that include a strong, technology-based teacher training component and do not require on-site trainers. Coupled with a strong and comprehensive set of student materials, such a technologically-based teacher training program can be used by typical teachers to improve students' knowledge and use of reading comprehension strategies. Future research should focus on determining the most effective elements of such a program and how those elements can be configured to be both most effective in preparing teachers to teach reading comprehension strategies and inviting to teachers.

\section{Acknowledgement}

This research was funded under grant \# R305S050072 from the U. S. Department of Education, Institute of Education Sciences' Small Business Innovation Research (SBIR) program. The content or this article does not necessarily reflect the views of the IES or any other agency of the U. S. government.

\section{References}

ACT. (2006). Reading between the lines: What the ACT reveals about college readiness in reading. Iowa City, IA: Author.

Anderson, V. (1992). A teacher development project in transactional strategy instruction for teachers of severely reading-disabled adolescents. Teaching \& Teacher Education, 8, 391-

403. 
Biancarosa, G., \& Snow, C. E. (2004). Reading next-A vision for action and research in middle and high school literacy. A report to the Carnegie Corporation of New York: Washington, DC: Alliance for Excellent Education.

Brown, R., Pressley, M., Van Meter, P., \& Schuder, T. (1996). A quasi-experimental validation of transactional strategies instruction with low-achieving second grade readers. Journal of Educational Psychology, 88, 18-37.

Duffy, G. G. (2002). The case for direct explanation of strategies. In C. C. Block \& M. Pressley (Eds.), Comprehension instruction: Research-based best practices (pp. 28-41). New York: The Guilford Press.

Duffy, G. G., Roehler, L. R., Sivan, E., Rackliffe, G., Book, C., Meloth, M., Vavrus, L. G., Wesselman, R., Putnam, J., \& Bassiri, D. (1987). Effects of explaining the reasoning associated with using reading strategies. Reading Research Quarterly, 22, 347-368.

Duke, N. K., \& Pearson, P. D. (2002). Effective practices for developing reading comprehension. In A. E. Farstrup \& S. J. Samuels (Eds.), What research has to say about reading instruction (3rd ed., pp. 204-242). Newark, DE: International Reading Association.

Ellery, V. (2005). Creating strategic readers. Newark, DE: International Reading Association.

Elliot, A. J., \& Dweck, C. S. (2005). Handbook of competence and motivation. New York: Guilford.

Gambrell, L. (2007). Sundance comprehension strategies kit. Northborough, MA: Sundance Publishing.

Graves, M. F., Juel, C., \& Graves, B. B. (2007). Teaching reading in the 21st century (4th ed.). Boston: Allyn \& Bacon.

Graves, M. F., \& Liang, L. A. (2003). On-line resources for fostering understanding and higher-level thinking in senior high school students. Schallert, D. L., Fairbanks, C. M., Worthy, J. Maloch, B., \& Hoffman, J. V. (Eds.), 51st Yearbook of the National Reading Conference Yearbook (pp. 204-215). Oak Creek, WI: National Reading Conference.

Graves, M. F., \& Philippot, R. A. (2002, December). Time given to preparing reading teachers: Is it sufficient? Paper presented at the 51st Annual Meeting of the National Reading Conference, Miami.

Guthrie, J. T., Wigfield, A., \& Perencevich, K. C. (2004). Motivating reading comprehension. Mahwah, NJ: Erlbaum. Making Meaning. (2003). Berkeley, CA: Developmental Learning Center.

Israel, S. E., \& Duffy, G. G. (2008). Handbook of research on reading comprehension. New York: Routledge.

Kamil, M. L., Borman, G. D., Dole, J., Kral, C. C. Salinger, T., \& Torgesen, J. (2008). Improving adolescent literacy: Effective classroom intervention practices. Washington, DC: National Institute of Education.

Kennedy, A.M., Mullis, I.V.S., Martin, M.O., \& Trong, K.L. (2007). PIRLS 2006 encyclopedia: A guide to reading education in the forty PIRLS 2006 countries. Chestnut Hill, MA: Boston College. 
Lee, J., Grigg, W., \& Donahue, P. (2007). The Nation's Report Card: Reading 2007 (NCES 2007-496). National Center for Education Statistics, Institute of Education Sciences, U.S. Department of Education, Washington, D.C.

Lee, J., \& Weiss, A. (2007).The Nation's Report Card: U.S. History 2006 (NCES 2007-474). U.S. Department of Education, National Center for Education Statistics. Washington, D.C.: U.S. Government Printing Office.

National Association of State Boards of Education. (2005). Reading at risk: The report of the NASBE study group on middle and high school literacy. Alexandria, VA: Author.

National Reading Panel. (2000). Report of the National Reading Panel: Teaching children to read. Bethesda, MD: National Institute of Child Health and Human Development.

National Research Council. (2004). Engaging schools. Washington, DC: National Academies Press.

Pearson, P. D. (2000). Reading in the twentieth century. In T. L. Good \& M. Early (Eds.), American education: Yesterday, today, and tomorrow. Chicago: National Society for the Study of Education.

Pearson, P. D., Roehler, L .R., Dole, J. A., \& Duffy, G. G. (1992). Developing expertise in reading comprehension. In Samuels, S .J. \& Farstrup, A. E. (Eds.), What research has to say about reading instruction (2nd ed.). Newark, Del.: International Reading Association, pp. 145199).

Perie, M., \& Moran, R. (2005). NAEP 2004 Trends in Academic Progress: Three Decades of Student Performance in Reading and Mathematics (NCES 2005-464). U.S. Department of Education, Institute of Education Sciences, National Center for Education Statistics. Washington, DC: Government Printing Office.

Pressley, M. (2006, April). What the future of reading research could be. Paper presented at the International Reading Association's Reading Research 2006, Chicago.

Pressley, M. (2002). Comprehension strategies instruction: A turn of the century report. In C. C. Block \& M. Pressley (Eds.), Comprehension instruction: Research-based best practices (pp. 11-27). New York: The Guilford Press.

Pressley, M. (2000). What should reading comprehension instruction be the instruction of? In M. Kamil, P. Mosenthal, P. D. Pearson, \& R. Barr (Eds.), Handbook of reading research, volume 3 (pp. 545-561). Mahwah, NJ: Erlbaum.

Pressley, M., \& El-Dinary, P. B. (1997). What we know about translating comprehension strategies instruction research into practice. Journal of Learning Disabilities, 30, 486-488.

Pressley, M., El-Dinary, P. B., Gaskins, I., Schuder, T., Bergman, J. L., Almasi, J., \& Brown, R. (1992). Beyond direct explanation: Transactional instruction of reading comprehension strategies. Elementary School Journal, 92, 511-554.

Programme for International Student Assessment. (2004). Learning for tomorrow's world. Paris: Organization for Economic Co-operation and Development.

RAND Reading Study Group. (2002). Reading for understanding: Toward an R\&D program in reading comprehension. Santa Monica, CA: RAND Education. 
Reading Explorations. (2002). Bloomington, MN: PLATO Learning.

Reutzel, D. R., Fawson, P. C. \& Smith, J. A. (2003, December). Teaching comprehension strategies using information texts. Paper presented at the annual meeting of the National Reading Conference, Scottsdale, AZ.

Correspondence: Gregory C. Sales, President and CEO, Seward Incorporated, 2200 East Franklin Avenue, Minneapolis, MN 55404, United States. 